\title{
Self-desiccation of a vernacular CSA binder
}

\section{Conference Paper}

Author(s):

Pires Martins, Natalia (D); Cicek, Burhan; Brumaud, Coralie; Habert, Guillaume

Publication date:

2022-01

Permanent link:

https://doi.org/10.3929/ethz-b-000512120

Rights / license:

In Copyright - Non-Commercial Use Permitted

Originally published in:

1, https://doi.org/10.4028/www.scientific.net/CTA.1.339

\section{Funding acknowledgement:}

812580 - European Training Network for the remediation and reprocessing of sulfidic mining waste sites (EC) 


\title{
SELF-DESICCATION OF A VERNACULAR CSA BINDER
}

\author{
N. P. Martins ${ }^{1 *}$, B. Cicek $^{2}$, C. Brumaud ${ }^{1}$, G. Habert ${ }^{1}$ \\ ${ }^{1}$ Chair of Sustainable Construction, ETH Zürich, Switzerland \\ ${ }^{2}$ Chair of Design and Structural Systems, Bauhaus-University Weimar, Germany \\ ${ }^{*}$ Corresponding author; e-mail: martins@ibi.baug.ethz.ch
}

\begin{abstract}
The fast precipitation of ettringite in conventional Calcium Sulfo Aluminate (CSA) cement causes rapid stiffening of the cement paste and is directly associated with short setting times and selfdesiccation. To extend the time during which those types of cement remain workable, retarding admixtures can be used. However, retarders may affect the amounts and types of hydration products formed and as a consequence the ability of hydrated cement to chemically bind water. This work investigates the influence of two natural-based admixtures on the self-desiccation ability of a vernacular CSA ternary binder used as earth stabilization. Vicat measurements were used to study the efficiency of citric acid and sucrose as retarding admixtures on the setting time of stabilized earth. A quantitative study of the self-desiccation ability of the binder was performed on dried binder pastes using thermogravimetric analysis (TGA). Results show that both admixtures have a significant impact on the setting time of the binder. Furthermore, TGA showed that the selfdesiccation ability of this vernacular CSA binder is significantly reduced when citric acid at high dosages is used, both at early hydration and after 14 days. On the contrary, the use of sucrose does not affect the water chemically bound at an early age but can maximize bound water after 14 days of hydration.
\end{abstract}

Keywords:

Alternative binder; Stabilized earth; Ettringite binder; Retarding admixtures; Sucrose; Citric acid

\section{INTRODUCTION}

The development of alternative low-carbon binders for earth stabilization is desired in the context of reducing the $\mathrm{CO}_{2}$ emissions from construction. Similar carbon footprint to concrete was observed in self-compacted clay-based concrete (SCCC) formulations containing commercial CSA cement (Scrivener et al., 2018). Previous works (Cicek et al., 2020, 2019) have shown that ternary binders produced from lime, gypsum, and natural pozzolan can be used to stabilize earth mixtures. Considerable improvements in water resistance and compressive strength have been observed in stabilized earth mixtures. Their application in advanced building processes which require proper binder design and control of hydration, however, demands also the control of other properties such as setting time and self-desiccation. For instance, in earth construction applications, dry internal environments caused by selfdesiccation may be beneficial to develop early age strength in self-compacted clay-based concrete (OuelletPlamondon and Habert, 2016) and to adjust the time of formwork removal when time constraints are present. In reinforced concrete applications, self-desiccation is desired because it leads to the protection of the reinforcement against corrosion, even in chloride-rich environments (Glasser and Zhang, 2001).

Self-desiccation is the ability to reduce moisture and to reach a dry internal environment by binding free water within hydrates. It is an intrinsic property brought by ettringite formation, since ettringite has a high internal drying capacity i.e. $85 \%$, compared with $30 \%$ for $\mathrm{C}-\mathrm{S}-\mathrm{H}$, due to its water-rich structure (Ideker et al., 2019). In commercial CSA cement, self-desiccation depends on the cement composition, calcium sulfate source, W/C ratio, and curing conditions (Coumes et al., 2019). In alternative ettringite-binders, this property has not yet been quantified.

Setting time can be adjusted by the use of chemical admixtures commonly used in cement products i.e. accelerators and set retarders. In ettringite-binders, especially those containing gypsum hemihydrate as a sulfate source, the use of retarders is often necessary to prolong the period in which the material remains workable and to enable large-scale applications. For OPC, set retarders can be found in a variety of sugars, organic acids, phosphates, phosphonates, lignosulfonates, and polycarboxylate ether (PCE) superplasticizers (Reiter et al., 2020). For binary and ternary CAC binders and CSA systems involving a calcium sulfate source, retardation can be achieved by the use of citric (Burris and Kurtis, 2018; Nguyen et al., 2019; Pelletier et al., 2010), tartaric, and phosphoric acid (Reiter et al., 2020), sodium gluconate (Pelletier-Chaignat et al., 2011), sodium-potassium tartrate, borax (Zajac et al., 2016) and styrene-butadiene copolymer dispersion (Li and Wang, 2019). Nevertheless, despite being considered 
an excellent retarder of cement hydration (Thomas and Birchall, 1983), investigations on the effect of sucrose used as a set retarder in CSA cement and other types of ettringite-based binders are rare. This work investigates how the use of sucrose and citric acid as natural-based chemical admixtures affects the self-desiccation ability of a vernacular CSA ternary binder.

\section{MATERIALS AND METHODS}

Laboratory grade calcium hydroxide and calcium sulfate hemihydrate i.e. plaster of Paris were added to a natural pozzolan (trass (Tubag, Germany)), to recreate a vernacular CSA binder. The materials were blended at ambient temperature using a high-speed mixer. The final composition of the binder in terms of calcium, sulfur, and aluminum oxide is shown in Fig. 1.

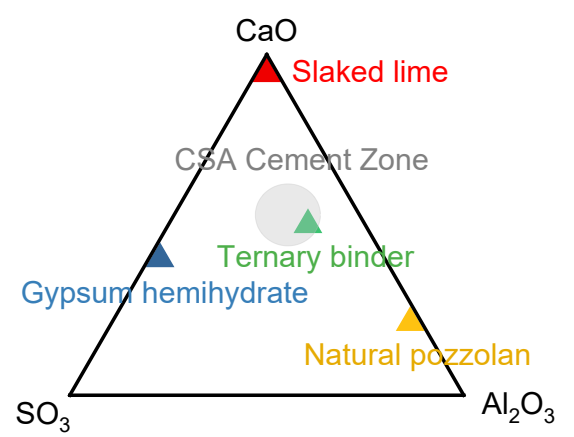

Fig. 1: Composition of the vernacular CSA ternary binder and its components.

The binder was added to a mixture of commercially available mineral earth material (Stroba Naturbaustoffe Ag, Switzerland) and standard sand (SNL, France), to produce stabilized earth mixtures. Tab. 1 presents the mineralogy of the earth material and the pozzolan (trass) used in this study.

Tab. 1: Mineralogy of natural pozzolan and earth material.

\begin{tabular}{lcc}
\hline & Natural pozzolan & Earth material \\
\hline Anastase & - & $<0.5$ \\
Calcite & 8 & $<0.5$ \\
Chlorite & 5 & 1 \\
Goethite & - & 9 \\
Kaolinite & - & 21 \\
Microcline & - & 2 \\
Muscovite/llite & 13 & 25 \\
Plagioclase-Albite & 9 & 1 \\
Pyrite & - & $<0.5$ \\
Quartz & 13 & 21 \\
Rutile & $<0.5$ & 2 \\
Smectite & - & 17 \\
Analcime & 14 & - \\
Sanidine & 32 & - \\
Biotite & 7 & - \\
\hline
\end{tabular}

Two different retarding admixtures were used i.e. sucrose and citric acid. Each was dissolved in the mixing (deionized) water before the production of the binder pastes/stabilized earth mixtures.

Stabilized earth mixtures (1:1.16:1.71, binder:earth:sand wt.\%; water/binder $=1.0)$ produced using different ratios of retarding admixtures had their setting time measured in triplicates using an automatic Vicat apparatus (Vicatronic, Matest). The Vicat apparatus was placed in a closed box to minimize moisture losses due to evaporation.

The self-desiccation ability of the mixtures was investigated in terms of water chemically bound by the binder. Binder pastes $(W / B=1.0)$ were produced with different dosages of retarding admixture and hydrated in sealed containers until the day of the measurement. Before TGA analysis, the aged paste samples underwent hydration stoppage procedure using the solvent exchange method with isopropanol and diethyl ether, after which they dried in a vacuum desiccator until constant mass. Samples (approximately 15mg) were measured by thermogravimetry (STA 449 F5 Jupiter, Netzsch, Switzerland) in the $20-1000^{\circ} \mathrm{C}$ range using $20 \mathrm{~K} / \mathrm{min}$ heating rate and inert atmosphere. The bound water was calculated as the mass loss at $550^{\circ} \mathrm{C}$. 


\section{RESULTS}

The start and end of the setting of each stabilized earth mixture were obtained from the averaged penetration curves illustrated in Fig. 2. The reference sample, which does not contain a retarder, has its dormant period until the end of the first 2 hours after mixing. After that point, the hydration reactions start to take place and modify the microstructure of the sample. As the newly formed hydration products start to connect the solid phases, a decrease in needle penetration is observed. After 10 hours, the loss in internal moisture, mostly due to chemical drying, prevents the needle from penetrating beyond the surface of the sample.

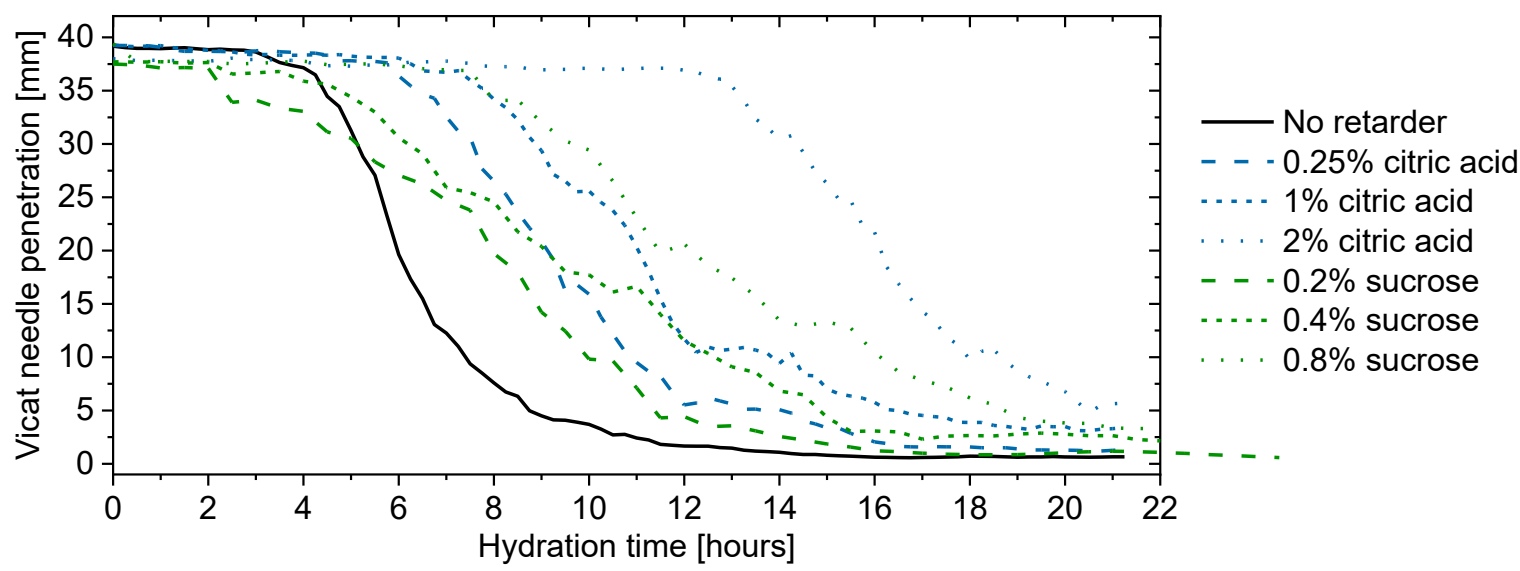

Fig. 2: Averaged penetration curves of earth mixtures containing different dosages of retarding admixtures.

The samples containing citric acid present higher values of initial and final set, which is an indication that citric acid delays the onset of hydration; yet, it does not seem to modify the rate at which hydration occurs. A delay of up to 9 hours is observed in the initial setting when $2 \%$ citric acid is used.

The effect of the dosages of sucrose on the final setting of the stabilized earth mixtures is pronounced, indicating a setting prolongation effect, rather than a setting retardation (Fig. 2). The slopes of the green curves, on the other hand, suggest that sucrose affects the rate of hydration of the samples. Furthermore, this effect seems to be enhanced when sugar dosage increases.

In Fig. 3, the measured bound water values on binder pastes produced with different admixtures are plotted as a function of their increasing dosages. The chemical drying resulting from hydration reactions on paste samples containing sucrose is nearly the same as in the reference sample on the first 24 hours after mixing, regardless of the sugar dosage. At the same hydration age, however, the binding water ability of pastes containing citric acid is sensitive to the citric acid dosage. The increase in citric acid dosage adversely affects the self-desiccation ability of the binder; the samples containing $1.0 \%$ citric acid bound $7.0 \mathrm{mg}$ of water $/ \mathrm{mg}$ of binder, in contrast with $10.5 \mathrm{mg}$ of water/mg of binder in the reference sample.

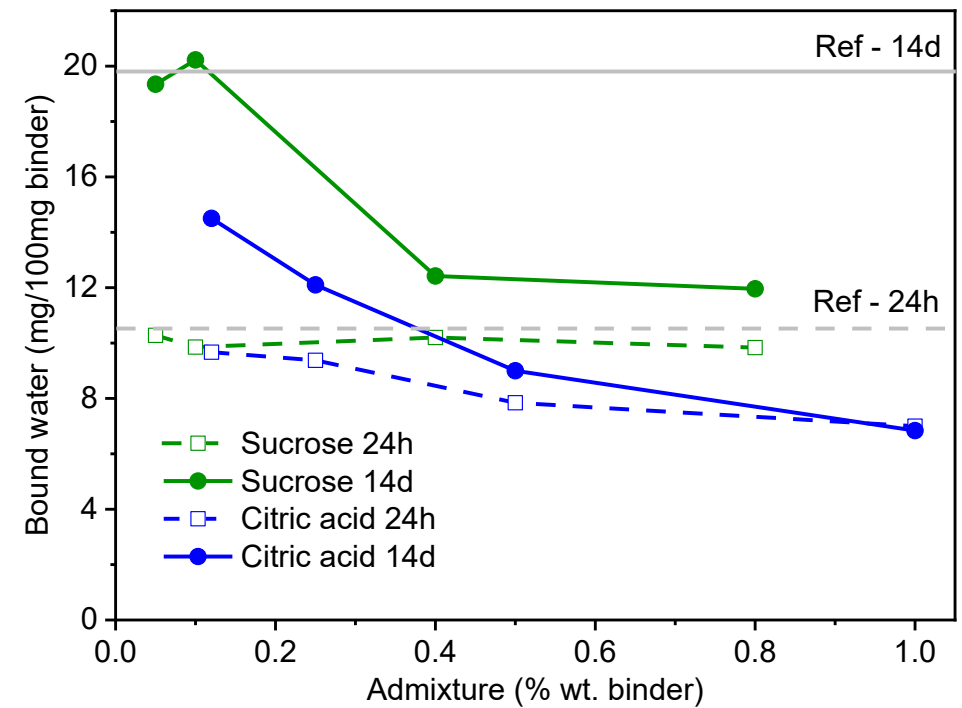

Fig. 3: Chemically bound water in paste samples containing sucrose (green) and citric acid (blue) hydrated for 24 hours (dashed lines) and 14 days (solid lines). The reference values correspond to samples that do not contain retarding admixtures.

After longer hydration time, the samples present higher values of bound water, which suggests that hydration progresses and hydration products continue to form. Pastes containing lower sucrose dosages present bound water values equivalent to the reference. The pastes containing higher dosages of sucrose and all pastes containing citric acid, however, are not able to recover the self-desiccation ability within the studied timeframe. 


\section{DISCUSSION}

Results show that, as lower sucrose dosages seem to accelerate the start of setting of stabilized earth mixtures, all ratios investigated show to be efficient in delaying their final setting. That translates into significant setting prolongation and an apparent decrease in the rate at which hydration takes place when compared to the reference. There are reports of preferential adsorption of sucrose onto portlandite (Marchon and Flatt, 2016), which can be the cause of the retardation induced by sucrose in this ternary binder. The reason behind the apparent acceleration observed at lower sucrose dosages is not yet clear.

On the other hand, the consistent retarding effect of citric acid was seen both in the initial and final setting. That behavior has been observed before in gypsum plaster (Badens et al., 1999; Lanzón and García-Ruiz, 2012; Zhang et al., 2020), a material in which citric acid is used as an established retarder. In this case, the retardation is caused by the inhibition of hemihydrate dissolution (Lanzón and García-Ruiz, 2012).

The type and amount of retarder, besides having a clear effect on the setting time of stabilized earth mixtures, significantly influence the self-desiccation ability of the binder. A general reduction in the water uptake was observed on samples containing admixtures; particularly on samples containing citric acid. The connection between those effects requires further investigation on what specific modifications the admixtures can cause to the formation of hydration products. Fig. 4 shows the $35^{\circ} \mathrm{C}-550^{\circ} \mathrm{C}$ range of DTG curves obtained from the TGA measurements of binder pastes. The mass losses of ettringite, gypsum hemihydrate, and gypsum dihydrate present due to dehydration are visible between $35^{\circ} \mathrm{C}$ and $170^{\circ} \mathrm{C}$ (Lothenbach et al., 2015).

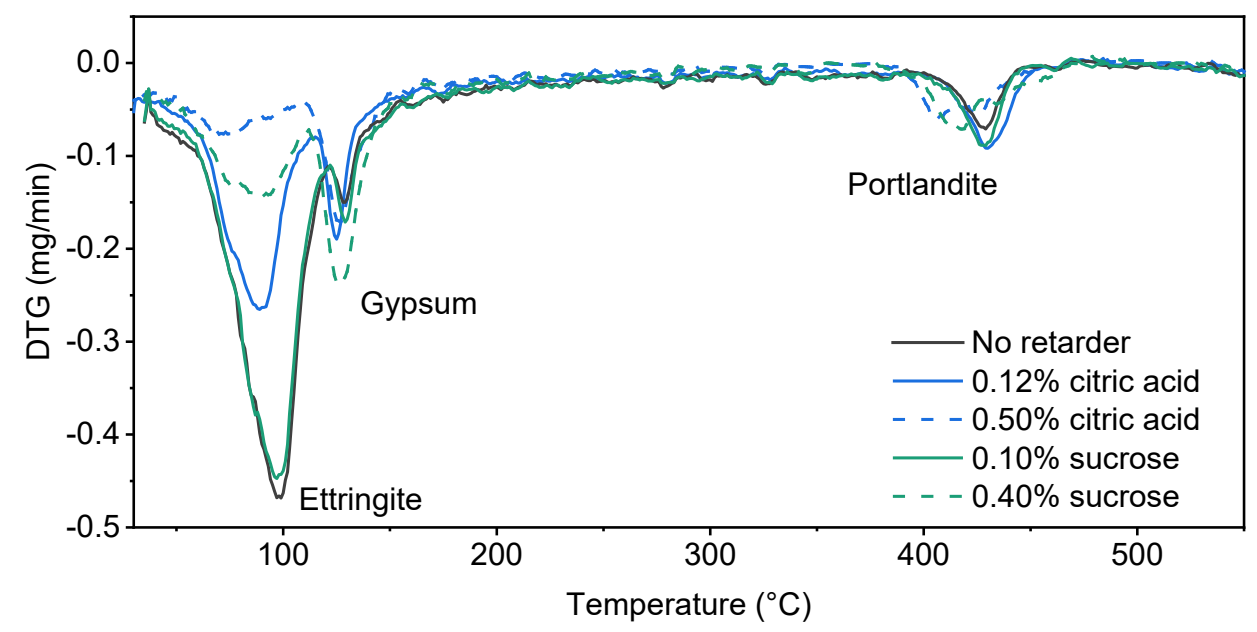

Fig. 4: DTG curves of binder pastes containing citric acid (blue) or sucrose (green) hydrated for 14 days. The reference values correspond to samples that do not contain retarding admixtures.

Fig. 4 indicates that ettringite and gypsum are formed during the hydration of this ternary binder, and their relative amounts are affected by the use of admixtures. Furthermore, the most striking differences between the curves can be seen within the temperature range that corresponds to dehydration of ettringite. Being the main hydration product of this ternary binder, ettringite governs its binding water ability and, hence, the self-desiccation of the stabilized earth mixtures.

\section{CONCLUSIONS}

Setting time and self-desiccation are application-specific properties that can be controlled by the use of admixtures. This work investigated how these properties are affected by adding sucrose or citric acid to earth mixtures stabilized using a vernacular CSA binder.

The results showed that the use of sucrose and citric affect both properties very differently. Despite the consistent contribution to retard setting, citric acid significantly reduces the binding water ability of this ternary binder, particularly with increasing dosage and at a later age (14 days). Conversely, the effect on the self-desiccation ability of the studied mixtures is less detrimental when sucrose is used as a retarder. Lower dosages of sucrose $(0.05 \%$ and $0.1 \% \mathrm{wt} . \%$ ) lead to only a minor change in bound water values compared to the reference samples. However, sucrose affects the rate of reaction of the mixtures and may accelerate the setting at low dosages. The distinct retardation effects observed for each admixture suggest that the retardation is caused by mechanisms of different nature.

The modifications on the hydration of the mixtures caused by each retarder could be seen on the initial and final setting curves and looking at the bound water values. Those observations are in agreement with the qualitative thermogravimetric results, which suggest that ettringite formation is the main phase governing the self-desiccation ability of this ternary binder.

\section{ACKNOWLEDGMENTS}

This project has received funding from the European Union's EU Framework Programme for Research and Innovation Horizon 2020 under Grant Agreement \#812580. 


\section{REFERENCES}

Badens, E., Veesler, S., Boistelle, R., 1999. Crystallization of gypsum from hemihydrate in presence of additives. J. Cryst. Growth 198-199, 704-709. https://doi.org/10.1016/S0022-0248(98)01206-8

Burris, L.E., Kurtis, K.E., 2018. Influence of set retarding admixtures on calcium sulfoaluminate cement hydration and property development. Cem. Concr. Res. 104, 105-113. https://doi.org/10.1016/j.cemconres.2017.11.005

Cicek, B., Martins, N.P., Brumaud, C., Habert, G., 2019. CSA as A Revisited Vernacular Technique for Earth Stabilization, in: 2nd International Conference of Sustainable Building Materials.

Cicek, B., Martins, N.P., Brumaud, C., Habert, G., Plötze, M., 2020. A Revisited Vernacular Stabilization Technique for a Durable Earth-Mix, in: LEHM 2020 Proceedings. p. 2425.

Coumes, C.C.D., Farcy, O., Antonucci, P., Champenois, J.B., Lambertin, D., Mesbah, A., 2019. Design of selfdesiccating binders using CSA cement: Influence of the cement composition and sulfate source. Adv. Cem. Res. 31, 178-194. https://doi.org/10.1680/jadcr.18.00100

Glasser, F.P., Zhang, L., 2001. High-performance cement matrices based on calcium sulfoaluminate-belite compositions. Cem. Concr. Res. 31, 1881-1886. https://doi.org/10.1016/S0008-8846(01)00649-4

Ideker, J.H., Scrivener, K.L., Fryda, H., Touzo, B., 2019. Calcium aluminate cements, Lea's Chemistry of Cement and Concrete. https://doi.org/10.1016/B978-0-08-100773-0.00012-5

Lanzón, M., García-Ruiz, P.A., 2012. Effect of citric acid on setting inhibition and mechanical properties of gypsum building plasters. Constr. Build. Mater. 28, 506-511. https://doi.org/10.1016/j.conbuildmat.2011.06.072

Li, L., Wang, R., 2019. Early hydration of CSA cement modified with styrene-butadiene copolymer dispersion. Adv. Cem. Res. 1-14. https://doi.org/10.1680/jadcr.19.00038

Lothenbach, B., Durdziński, P., De Weerdt, K., 2015. Thermogravimetric analysis (TGA), in: A Practical Guide to Microstructural Analysis of Cementitious Materials. CRC Press, pp. 91-102. https://doi.org/10.1201/b19074

Marchon, D., Flatt, R.J., 2016. Impact of chemical admixtures on cement hydration, Science and Technology of Concrete Admixtures. Elsevier Ltd. https://doi.org/10.1016/B978-0-08-100693-1.00012-6

Nguyen, H., Kinnunen, P., Gijbels, K., Carvelli, V., Sreenivasan, H., Kantola, A.M., Telkki, V.-V., Schroeyers, W., Illikainen, M., 2019. Ettringite-based binder from ladle slag and gypsum - The effect of citric acid on fresh and hardened state properties. Cem. Concr. Res. 123, 105800. https://doi.org/10.1016/j.cemconres.2019.105800

Ouellet-Plamondon, C.M., Habert, G., 2016. Self-Compacted Clay based Concrete (SCCC): Proof-of-concept. J. Clean. Prod. 117, 160-168. https://doi.org/10.1016/j.jclepro.2015.12.048

Pelletier-Chaignat, L., Winnefeld, F., Lothenbach, B., Saout, G. Le, Müller, C.J., Famy, C., 2011. Influence of the calcium sulphate source on the hydration mechanism of Portland cement-calcium sulphoaluminate clinkercalcium sulphate binders. Cem. Concr. Compos. 33, 551-561. https://doi.org/10.1016/j.cemconcomp.2011.03.005

Pelletier, L., Winnefeld, F., Lothenbach, B., 2010. The ternary system Portland cement-calcium sulphoaluminate clinker-anhydrite: Hydration mechanism and mortar properties. Cem. Concr. Compos. 32, 497-507. https://doi.org/10.1016/j.cemconcomp.2010.03.010

Reiter, L., Wangler, T., Anton, A., Flatt, R.J., 2020. Setting on demand for digital concrete - Principles, measurements, chemistry, validation. Cem. Concr. Res. 132, 106047. https://doi.org/10.1016/j.cemconres.2020.106047

Scrivener, K.L., John, V.M., Gartner, E.M., 2018. Eco-efficient cements: Potential economically viable solutions for a low-CO2 cement-based materials industry. Cem. Concr. Res. 114, 2-26. https://doi.org/10.1016/j.cemconres.2018.03.015

Thomas, N.L., Birchall, J.D., 1983. The retarding action of sugars on cement hydration. Cem. Concr. Res. 13, 830842. https://doi.org/10.1016/0008-8846(83)90084-4

Zajac, M., Skocek, J., Bullerjahn, F., Ben Haha, M., 2016. Effect of retarders on the early hydration of calciumsulpho-aluminate (CSA) type cements. Cem. Concr. Res. 84, 62-75. https://doi.org/10.1016/j.cemconres.2016.02.014

Zhang, Y., Yang, J., Cao, X., 2020. Effects of several retarders on setting time and strength of building gypsum. Constr. Build. Mater. 240, 117927. https://doi.org/10.1016/j.conbuildmat.2019.117927 